\title{
Sütçü İneklerde Pnömovagina ile Açlık Çukurluğu Derinliği Arasındaki ilişkinin Belirlenmesi: Ön Çalışma
}

\author{
E. Sinem ÖZDEMIR SALCI ${ }^{1 *}$, Kamil SEYREK INTAŞ ${ }^{1}$ \\ ${ }^{1}$ Uludağ Üniversitesi, Veteriner Fakültesi, Doğum ve Jinekoloji Anabilim Dalı, Görükle Kampüsü, Bursa, Türkiye.
}

Geliş Tarihi: 11.05.2018

Kabul Tarihi: 13.06.2018

\begin{abstract}
Özet: Bu ön çalışmada, ineklerde, açlık çukurluğu derinliği ile anüs çöküklüğü ölçümlerinin pnömovagina ile bir korelasyonu olup olmadığının araştırılması amaçlanmıştır. Çalışma materyalini 96 adet sağlıklı (Grup I) ve 46 adet pnömovaginalı (Grup II) inekler oluşturdu. İnekler ayrıca vulva açılarına göre de grup A: $0-10^{\circ}(n=62)$, grup B: $10-30^{\circ}(n=51)$, grup C: $30-55^{\circ}(n=22)$ ve grup $D:>55^{\circ}(n=7)$ olarak derecelendirildi. Açlık çukurluğu derinliği ve anüs çöküklüğü ölçümleri sırasıyla: Grup I=6.03 \pm 2.08 ; 5.07 \pm 1.90 ; Grup $I I=8.07 \pm 1.84 ; 7.5 \pm 2.62$; Grup $A=5.85 \pm 2.15$; $4.77 \pm 1.92$; Grup $B=6.75 \pm 1.93 ; 5.74 \pm 1.56$; Grup $C=8.00 \pm 1.93$; 7.32 \pm 2.28 ; Grup $D=8.81 \pm 2.30 ; 10.71 \pm 1.87 \mathrm{~cm}$ olarak bulundu. Açlık çukurluğu derinlikleri ve anüs çöküklüğü ölçümleri yönünden; Grup I ve II arasında anlamlı fark bulundu ( $P=0.000)$. Grup $A, B, C$ ve $D$ arasında ise açlık çukurlukları derinliği ölçümleri bakımından, grup $A$ ile $C$ ve $D(P=0.000 ; P=0.002)$; anüs derinliği ölçümleri yönünden ise tüm gruplar arasındaki fark anlamlı bulundu $(P<0.05)$. Açlık çukurluğu ölçümleri ile anüs çöküklüğü ölçümleri arasında sadece Grup I $(P=0.012$; $r=0.256)$ ve grup $A^{\prime}$ da $(P=0.037 ; r=0.266)$ anlamlı ve pozitif bir korelasyon bulundu. Sonuç olarak, açlık çukurluğu derinliği ölçümü ineklerde pnömovaginanın tanısında kullanılabilecek önemli bir kriter olduğu, bu amaçla açlık çukurluğu ile anüs çöküklüğü ölçümlerinin standardize edilerek birlikte kullanılmalarının uygun olacağı kanısına varıldı.
\end{abstract}

Anahtar Kelimeler: Açlık çukurluğu derinliği, Anüs çöküklügü, Inek, Pnömovagina, Vulva açısı.

\section{Determination of the Correlation between Pneumovagina and Depth of the Paralumbar Fossa in}

Dairy Cows: A Preliminary Study

\begin{abstract}
In this preliminary study, it was aimed to investigate whether there is a correlation between pneumovagina and the depth of the paralumbar fossa and anus in cows. The materials of the study consisted of 96 healthy cows (Group I) and 46 cows with pneumovagina (Group II). The cows were also grouped according to the vulvar angle; group A: 0-10 $(n=62)$, group B: $10-30^{\circ}(n=51)$, group C: $30-55^{\circ}(n=22)$ and group $D:>55^{\circ}(n=7)$. The measurements of the depth of the paralumbar fossa and anus were as follows respectively: Group I=6.03 \pm 2.08 ; $5.07 \pm 1.90$; Group II=8.07 \pm 1.84 ; 7.5 \pm 2.62 ; Group $A=5.85 \pm 2.15 ; 4.77 \pm 1.92$; Group $B=6.75 \pm 1.93 ; 5.74 \pm 1.56$; Group $C=8.00 \pm 1.93 ; 7.32 \pm 2.28$; Group $D=8.81 \pm 2.30 ; 10.71 \pm 1.87$ $\mathrm{cm}$. In terms of the depths of paralumbar fossa and anus, there was significant difference between Group I and II $(P=0.000)$. Among the groups $A, B, C$ and $D$, significant difference was found between group $A$ and $C$ and $D(P=0.00 ; P=0.002)$ in terms of the depth of paralumbar fossa; between all groups in terms of the depth of anus $(P<0.05)$. There was a significant and positive correlation between the depth of paralumbar fossa and anus measurements only in Group I $(P=0.012 ; r=0.256)$ and in group $A(P=0.037 ; r=0.266)$. As a result, the measurement of the depth of the paralumbar fossa was found to be an important criterion that can be used in the diagnosis of pneumovagina in cows and it is recommended to standardize and use measurements of the depth of paralumbar fossa and anus together.

Keywords: Cow, Depth of the anus, Depth of the paralumbar fossa, Pneumovagina, Vulvar angle.
\end{abstract}

\section{Giriş}

Infertilite, sütçü inek yetiştiriciliğinde sıklıkla karşımıza çıkan ve ciddi ekonomik kayıplara neden olan bir sorundur. Enfeksiyöz infertilitenin en önemli sebeplerinden biri pnömovaginadır (Sheldon ve ark., 2004; Kumru, 2009). Pnömovagina, farklı faktörlere bağlı olarak vulva dudaklarının ve hymenal sfinkterin yeteri derecede kapanmamasından dolayı vagina içerisine hava dolması ile karakterize bir patolojidir (Dehghani ve ark., 2011; Demet, 2010; Kumru, 2009). Pnömovagina sebebi ile vaginada bulunan hava irritasyon yaratır ve bu irritasyon sonucu şekillenen ıkınmaya bağlı olarak ya da hayvanın pasif hareketleri, abdominal kontraksiyon ve relaksasyon nedeniyle vulva dudaklarından spontan hava girişi ve çıkışı söz konusu olmaktadır (Kumru, 2009). Böylece pnömovagina sebebi ile genital kanala hava girişi ile birlikte vaginal kanala mikroorganizmalar da girerek vaginitis, servisitis ve endometiritise yol açarlar. Bu durum ineklerde verim kaybı, siklus bozukluğu, suni tohumlamalara yanıt alamama ve gebe kalma oranında önemli ölçüde düşme olarak yansır (Demet, 2010). Pnömovagina oluşumunun nedenleri; vulva dudaklarının, vestibulo vaginal sfinkterin kapanma bozukluğu, kötü perineal bölge konformasyonu, anatomik bozukluklar, güç doğum, 
doğum sırasında ya da darbelere bağlı vulva ve vaginanın travmatik yaralanması, (Dehghani ve ark., 2011; Demet, 2010; Youngquist ve Braun, 1993), ilerleyen yaş (Kien-Nguyen ve ark., 2014) ve kötü beslemedir. Pnömovagina görülen ineklerin vücut kondüsyon skoru genelde 2'nin altındadır (Sheldon ve ark., 2004). Anatomik olarak vulva, vestibular sfinkter ve serviks, uterusun diş ortamla kontamine olmasına yönelik mekanik engel sağlayan yapılardır (Youngquist ve Braun, 1993). Vulva açısının anüse olan eğimi farklı nedenlere bağlı olarak değiştiğinde; vagina, hava ve dışkıyı emmeye yatkınlaşır ve böylece vaginal kontaminasyon oluşur. Vulva dudakları anüse doğru eğik olan ineklerde, vulvaya fekal kontaminasyon şekillenir ve bu durum infertilite için predispozisyondur (Dehghani ve ark., 2011). Vulva açı ölçümlerinin pnömovagina gelişimi ve tespiti için önemli bir parametre olduğu bildirilmiştir (Kumru, 2009).

Pnömovagina olgularında vaginada köpüğün (hava ve mukus) bulunması patognomonik bir bulgudur. Hafif ve orta şiddetli olgularda östrusta köpüklü çara gözlenmesi en sık karşılaşılan klinik bulgudur. Şiddetli olgularda seksüel siklusun her safhasında hava girişi çıkışının duyulduğu bildirilmiştir (Kumru, 2009). Pnömovagina olgularının tanısında hava emme testi, vaginanın spekulum ile muayenesinde akıntı ya da hiperemi varlığı, rektal muayenede vaginadaki havanın dışarıya boşaltılması, uterusun transrektal ultrasonografisinde luminal yüzeyde hiperekoik görünüm, endometriyum sitoloji ve histopatolojik muayenesinde endometritis için yeterli sayıda nötrofil bulunması gibi bulgulardan birinin ya da birkaçının birden bulunması görülse de (Matyar, 2009), hava giriş çıkışının sürekli olmaması ve gözden kaçırılmasından dolayı klinik muayene bulgularına göre pnömovagina genellikle tanınamaz. Sunulan bu ön çalışmada pnömovagina tanısına yönelik yeni bir klinik bulgu elde etmek için açlık çukurluğu ölçümleri ile negatif abdominal basıncın, pnömovaginanın yapıcı sebeplerinden olabileceği hipotezini geliştirerek, ineklerde pnömovagina ile açlık çukurluğu derinliği arasındaki ilişkinin incelenmesi amaçlanmıştır.

\section{Materyal ve Metot}

Bu ön çalışma materyalini Bursa ilinde bulunan farklı yaş (2-8 yaş arası) ve ırktaki toplam 142 adet inek oluşturdu. Bu ineklerin 96'sında pnömovagina tespit edilmemiş (Grup I) ve 46'sında ise vulva dudaklarından belirgin hava emme tespit edilerek pnömovagina tanısı konulmuştur (Grup II), buna dayanarak inekler anamnez ve klinik muayene bulgularına göre pnömovagina yönünden negatif ve pozitif olarak sınıflandırıldı.

Yapılan genel muayenenin ardından, perineal bölgenin inspeksiyonu gerçekleştirildi. Anüsün, perineum ve vulvanın genel yapısı, üreme, yırtık vs. gibi herhangi bir yapısal değişiklik ya da patoloji olup olmadığı, vulva dudaklarının kapalı olup olmadığı, vulva kuruluğu, perivaginal bölgede herhangi bir akıntı olup olmadığı incelendi. Vulva açısı ölçümleri yapıldı. İneklerin açlık çukurluğu derinliği ve anüs çöküklüğü ölçümleri kayıt edildi. Açlık çukurluğu ölçümleri kumpas ve cetvel yardımı ile tuber coxa'dan son kostanın ortasına oblik şekilde yerleştirilen bir cetvelden açlık çukurluğunun en derin kısmına bir dikme indirilerek yapıldı (Şekil 1).

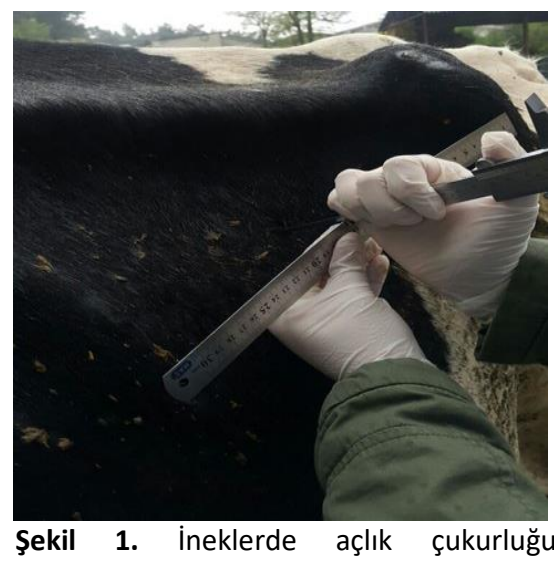
derinliğinin ölçümü.

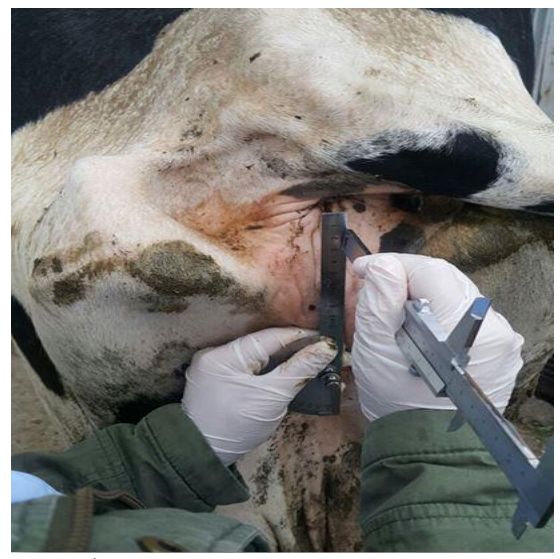

Şekil 2. Ineklerde anüs çöküklüğünün ölçümü.

Anüs çöküklüğü, arcus ischiadicum'dan yere indirilen bir dikme ile anüs arasındaki mesafe ölçülerek gerçekleştirildi (Şekil 2). Palpasyonda; pnömovaginanın tespiti için vulva dudakları aralanıp içeriye bastırılarak hava emme durumunun olup 
olmadığı kontrol edildi. Yapılan rutin klinik rektal ve transrektal ultrasonografik muayenede genital organlara ait herhangi bir patoloji olup olmadığı kontrol edildi ve vaginaya basınç uygulandığında vulvadan hava ya da pasif idrar çıkışı olup olmadığı gözlendi. Vaginanın spekulum ile muayenesinde vaginanın ve serviksin durumu, pnömovagina ve ürovaginaya ilişkin bulguların varlığı, vaginitis, hiperemi, konjesyon, vaginal akıntı varlığı ve varsa akıntının karakteri tespit edildi.

İnekler pnömovagina varlığına göre gruplandırıldığı gibi ayrıca vulva açılarına göre de grup A: $0-10^{\circ}(n=62)$, grup $B: 10-30^{\circ}(n=51)$, grup C: $30-55^{\circ}(n=22)$ ve grup $D:>55^{\circ}(n=7)$ olarak derecelendirildi.

Elde edilen tüm ölçümlere ait ortalama değer ve standart sapmalar bilgisayar programında hesaplandı (Microsoft ${ }^{\circledR}$ Excel, 2016, USA). Grup I ve II arasında açlık çukurluğu derinliği istatistiki olarak t-testi ile grup $A, B, C$ ve $D$ değerlendirmeleri ise One-Way Anova testi ile yapıldı. Açlık çukurluğu ile anüs çöküklüğü ölçümleri arasındaki korelasyonu değerlendirmek için ise Pearson korelasyon testi kullanıldı.

\section{Bulgular}

Çalışmada muayene edilen toplam 142 ineğin 46'sında pnömovagina tespit edildi ve pnömovagina prevelansı \%32.39 olarak belirlendi. Yapılan açlık çukurluğu derinliği ve anüs çöküklüğü ölçüm sonuçları Tablo 1'de verildi.

İstatistik analiz sonuçlarına göre Grup I ve II arasında açlık çukurluğu ve anüs derinlikleri arasında anlamlı fark bulundu $(P=0.000)$. Grup I'deki açlık çukurluğu derinliği ile anüs çöküklüğü arasında anlamlı ve pozitif bir korelasyon bulunurken $(P=0.012 ; r=0.256)$, grup II'de anlamlı bir korelasyon bulunmadı $(P=0.754)$.

Grup A, B, C ve D arasında açlık çukurlukları derinliği ölçümleri bakımından grup $A$ ile $C$ ve $D$ $(P=0.000 ; P=0.002)$ arasında anlamlı fark bulundu. Bunun yanında A ile $B(P=0.095)$; $B$ ile $C(P=0.086)$; $C$ ile $D(P=0.80)$ arasında istatistiki açıdan anlamlı fark bulunmadı. Anüs derinlikleri bakımından ise grup $A$ ile $B(P=0.034)$; $A$ ile $C(P=0.000)$; $A$ ile $D(P=0.000)$; $B$ ile $C(P=0.006)$; $B$ ile $D(P=0.000)$ ve $C$ ile $D(P=0.000)$ arasında anlamlı fark bulundu (Tablo 2). Açlık çukurluğu ölçümleri ile anüs çöküklüğü ölçümleri arasında sadece grup $A^{\prime}$ da anlamlı ve pozitif bir korelasyon bulundu $(P=0.037 ; r=0.266)$. Grup $B$ $(P=0.426)$, grup $C(P=0.427)$, Grup $D^{\prime}$ de $(P=0.759)$ korelasyon bulunmadı (Tablo 3 ).
Tablo 1. Gruplara ait açlık çukurluğu derinliği ve anüs çöküklüğü ölçümlerinin ortalama ve standart sapma değerleri.

\begin{tabular}{lcc}
\hline Gruplar & $\begin{array}{c}\text { Açlık Çukurluğu Derinliği } \\
(\mathbf{c m})\end{array}$ & $\begin{array}{c}\text { Anüs Çöküklüğü } \\
(\mathbf{c m})\end{array}$ \\
\hline Grup I & $6.03 \pm 2.08$ & $5.07 \pm 1.90$ \\
Grup II & $8.07 \pm 1.84$ & $7.5 \pm 2.62$ \\
Grup A & $5.85 \pm 2.15$ & $4.77 \pm 1.92$ \\
Grup B & $6.75 \pm 1.93$ & $5.74 \pm 1.56$ \\
Grup C & $8.00 \pm 1.93$ & $7.32 \pm 2.28$ \\
Grup D & $8.81 \pm 2.30$ & $10.71 \pm 1.87$ \\
\hline
\end{tabular}

Tablo 2. Gruplara ait açlık çukurluğu derinliği ve anüs çöküklüğü ölçümlerine ait istatistiksel sonuçlar.

\begin{tabular}{lcc}
$\begin{array}{l}\text { Grup } \\
\text { Karşılaştırmaları }\end{array}$ & Açlık Çukurluğu Derinliği & $\begin{array}{c}\text { Anüs } \\
\text { Çöküklüğü }\end{array}$ \\
\hline Grup I-II & $\mathrm{P}=0.000$ & $\mathrm{P}=0.000$ \\
Grup A-B & $\mathrm{P}=0.095$ & $\mathrm{P}=0.034$ \\
Grup A-C & $\mathrm{P}=0.000$ & $\mathrm{P}=0.000$ \\
Grup A-D & $\mathrm{P}=0.002$ & $\mathrm{P}=0.000$ \\
Grup B-C & $\mathrm{P}=0.086$ & $\mathrm{P}=0.006$ \\
Grup B-D & $\mathrm{P}=0.067$ & $\mathrm{P}=0.000$ \\
Grup C-D & $\mathrm{P}=0.80$ & $\mathrm{P}=0.000$ \\
\hline
\end{tabular}

Tablo 3: Gruplara ait açlık çukurluğu ile anüs çöküklüğü arasındaki korrelasyonlar.

\begin{tabular}{lc}
\hline Gruplar & Korrelasyon $(r)$ \\
\hline Grup I & $\mathrm{P}=0.012 ; r=0.256$ \\
Grup II & $\mathrm{P}=0.754 ; r=0.047$ \\
Grup A & $\mathrm{P}=0.037 ; r=0.266$ \\
Grup B & $\mathrm{P}=0.426 ; r=-0.144$ \\
Grup C & $\mathrm{P}=0.427 ; r=0.178$ \\
Grup D & $\mathrm{P}=0.759 ; r=-0.143$ \\
\hline
\end{tabular}

\section{Tartışma}

İneklerde karşılaşılan enfeksiyöz infertilitenin en önemli sebeplerinden birisi olan pnömovagina \%19.2 prevelansa sahiptir (Goncagül ve ark., 2012) ve süt sığırı yetiştiriciliği açısından önemli ekonomik kayıplara yol açmaktadır (Demet, 2010). Çalışmamız kapsamında değerlendirilen 142 adet ineğin 46 'sında pnömovagina tespit edilmiş olup bu problemin prevelansı \%32.39 olarak belirlendi.

Pnömovagina, anamnez bilgisi, perineal bölgenin inspeksiyonu, vulvanın palpasyonu, rektal muayene, vaginoskopi ve transrektal ultrasonografik muayene esnasında tanınabilir (Kumru, 2009; Youngquist ve Braun, 1993). Vulva açısının anüse olan eğimi, farklı nedenlere bağlı olarak değişerek vaginaya hava ve dışkı girişi için yatkınlığa sebep olup pnömovagina predispozisyonunu arttırır (Dehghani ve ark., 2011). Bu nedenle vulva açısı, pnömovaginanın tanısında önemli olduğundan çalışmamızda olgular vulva açısına göre de gruplandırıldı.

Farklı tür olan kısraklarda vulvanın arcus ischiadicum ile yapmış olduğu açı $10^{\circ}$ den büyük ise, bu olguların pnömovaginaya predispoze olduğu ve 
fertilitesinin ise azaldığı bildirilirken (Chenier, 2009), yine ineklerde, vulva açısı 45'den büyük olanların diğerlerine göre ürovaginaya predispoze olduğu bildirilir (Gautam ve Nakao, 2009). Bunun yanında ineklerde yapılan bir çalışmada, vulva açısı $20^{\circ}$ den büyük olan ineklerin pnömovaginaya predispoze olduğu ve özellikle vulva açı ölçümlerinin pnömovaginanın gelişimi, değerlendirilmesi ve tespiti için oldukça önemli bir parametre olarak değerlendirilmesi gerektiği bildirilmiştir (Goncagul ve ark., 2012; Kumru, 2009). Özetle, vulvanın dorsal ischiadic arch'a olan açısı $10-15^{\circ}$ den fazla ise pnömovagina ve dolayısıyla şekillenebilecek sekonder endometritis gözlenebilir (Kumru, 2009). Yapılan bir çalışmada pnömovaginalı 27 inekten 10 tanesinde vulva açısı $30^{\circ}$ (\%37), ve 17 tanesinde ise $45^{\circ}$ (\%62.9) olarak bulunmuştur (Dehghani ve ark., 2011). Sunulan çalışmamızdaki ineklerde vulva açısı 0-10 olanlar pnömovagina yönünden sağlıklı, 10 30 을 arasındaki inekler pnömovaginaya predispoze olarak değerlendirilirken, $30-55^{\circ}$ ve $55^{\circ}$ den büyük olanlar pnömovagina yönüyle pozitif olarak değerlendirildi. Bulgularımız yönüyle ise; vulva açısı $10^{\circ}$ ye kadar olan 62 inekte pnömovagina tespit edilmedi, 10 ile $30^{\circ}$ arasında olan 34 inekte pnömovagina negatif $(-)$ ve 17 'sinde pnömovagina pozitif $(+)$ olarak değerlendirilirken, $30^{\circ}$ den büyük olan 29 inekte ise pnömovagina saptandı

Klinik muayene bulgularına göre pnömovaginanın tespiti yapılabilmektedir (Youngquist ve Braun, 1993) ancak vaginada havanın sürekli bulunmayışı klinisyenler açısından yanıltıcı ve dolayısıyla klinik muayene bulgularına göre pnömovaginanın tanısını zorlaştıran bir durumdur. Bu nedenle; negatif abdominal basıncın olası pnömovagina yapıcı etkisi (Goncagul ve ark., 2012) düşünülerek ek bir bulgu olarak açlık çukurluğu ölçümlerinin pnömovagina ile ilişkisi sunulan çalışmamızda değerlendirmiştir. Doğumdan sonra uterus hızla invole olur ve laktasyon sırasında kötü kaliteli ve az miktarda kaba yem ile beslenen ineklerde, negatif enerji dengesi, vücut kondüsyon skorunda düşme ve abdominal yağ depolarında azalma oluşur. Bu abdominal boşluk hacmindeki azalma orta dereceden yüksek dereceye varan negatif abdominal basınca sebep olur. $\mathrm{Bu}$ da hymenal ve vulvar kapanma yetersizliklerinde vaginadan hava emilmesine yol açar (Goncagul ve ark., 2012). Açlık çukurluğu ölçümleri, pnömovaginalı ineklerde (Grup II) $8.07 \pm 1.84 \mathrm{~cm}$ ve sağlıklı ineklerde (Grup I) $6.03 \pm 2.08 \mathrm{~cm}$ olarak belirlendi. Açlık çukurluğu ölçümlerinin pnömovagina pozitif olan Grup II'de anlamlı bir şekilde daha derin olduğu belirlendi $(P=0.000)$. Açlık çukurluğu ölçümlerini vulva açısına göre gruplandırıldığında grup $A$ ile $C(P=0.000)$ ve $D$ $(P=0.002)$ arasında anlamlı fark olduğu ve ölçümlerin grup $C$ ve $D^{\prime}$ de daha derin olduğunu tespit edildi.

Şiddetli pnömovagina olgularında ineklerin perineal bölge konformasyonunda değişikliğin maksimum olması, özellikle bu ineklerde anüsün craniale doğru eğimlenmesi, anüsün vulvayı gerdirmesiyle birlikte vulvanın büyük ölçüde açılanması, ayrıca perianal yağ dokusundaki azalmaya bağlı olarak perineal atrofi şekillenmesi (Goncagul ve ark., 2012; Kumru, 2009), sunulan çalışmada da benzer bir durumun açlık çukurluğunda olabileceği ihtimalini düşündürmüştür. Sunulan çalışma bulguları incelendiğinde anüs çöküklüğünün pnömovaginalı ineklerde (Grup II) anlamlı bir şekilde daha derin olduğu görülmüştür $(P=0.000)$. Ayrıca inekler vulva açılarına göre gruplandırıldığında da, pnömovaginanın şiddeti ile anüs derinliği arasında doğru orantılı bir durum saptanmıştır.

Sonuç olarak, bu ön çalışma bulguları dikkate alındığında açlık çukurluğu ve anüs derinliği pnömovaginalı ineklerde daha fazla gözlemlenmiştir. Bu nedenle, açlık çukurluğu ve anüs derinliği ölçümü ineklerde pnömovaginanın tanısında bir belirteç olarak diğer tanı yöntemlerini destekleyen ve klinik sahada kullanılabilecek özellikte ölçüm yöntemidir. Ancak, gün içerisinde yem alımına bağlı olarak değişebilen açlık çukurluğu derinliği ve anüs çöküklüğü dikkate alınarak, ölçümlerin standardize edilmesinin gerekliliği kanaatine varılmıştır.

\section{Kaynaklar}

Chenier TS, 2009: Conditions of the external genitalia of mares. In "Current Therapy in Equine Medicine", Ed; Robinson NE and Sprayberry KA, 6th Edition, Chapter 168, Saunders, St. Louis, USA, pp. 764.

Dehghani SN, Yavari M, Kafi M, 2011: Treatment of pneumovaginitis in dairy cattle by caslick operation. Res Opin Anim Vet Sci, 1(6), 349-351.

Demet Ö, 2010: İneklerde pnömovagina olgusu; önemli bir döl tutmama sorunu. Dicle Üniv Vet Fak Derg, 1(1), 26-28.

Gautam G, Nakao T, 2009: Prevelance of urovagina and its effect on reproductive performance in Holstein cows. Theriogenology, 71, 1451-1461.

Goncagul G, Seyrek Intas K, Kumru IH, Seyrek Intas D, 2012: Prevalence and accompanying signs of pneumovagina and urovagina in dairy cows in the Southern Marmara region. Tierarztl Prax Ausg G, 6, 359-366. 
Kien-Nguyen C, Okouyi MWM, Hanzen Ch, 2014: A postmortem study of physiopathological characteristic of genital tracts of culled dairy cows in South Vietnam. In: Proceeding of th 9th International Ruminat Reproduction Symposium, Obhiro City, Japan, pp. 25-29.

Kumru IH, 2009: İneklerde pneumovagina ve ürovaginanın karşılaşııma sıklığı ve fertiliteye etkisi. Doktora Tezi. Uludağ Üniversitesi, Sağlık Bilimleri Enstitüsü, Doğum ve Jinekoloji Anabilim Dalı, Bursa, Türkiye.

Matyar G, 2009: Kısraklarda aşım sonrası geçici stapler (zımba) uygulamalarının gebe kalma oranı üzerine etkisi. Yüksek Lisans Tezi. Mustafa Kemal Üniversitesi, Sağlık Bilimleri Enstitüsü, Doğum ve Jinekoloji Anabilim Dalı, Hatay, Türkiye.
Sheldon IM, Barrett DC, Boyd H, 2004: The postpartum period. In:"Bovine Medicine. Diseases and Husbandry of Cattle", Ed; Andrews AH, Blowey RW, Boyd H, Eddy RG, 2nd Edition, Chapter 34, WileyBlackwell, St. Louis, USA, pp. 519.

Youngquist RS, Braun WF JR, 1993: Abnormalities of the tubular genital organs. Vet Clin North Am Food Anim Pract, 9, 309-322.

*Yazışma Adresi: E. Sinem ÖZdEMIR SALCI

Uludağ Üniversitesi, Veteriner Fakültesi, Doğum ve Jinekoloji Anabilim Dalı, Görükle Kampüsü, 16059, Bursa, TÜRKIYE

E-mail: ssalci@uludag.edu.tr 